\title{
Would ivermectin for malaria control be beneficial in onchocerciasis-endemic regions?
}

Joseph Nelson Siewe Fodjo ${ }^{1}$, Marina Kugler ${ }^{1}$, An Hotterbeekx ${ }^{1}$, Adam Hendy ${ }^{2}$, Jean-Pierre Van Geertruyden ${ }^{1}$ and Robert Colebunders ${ }^{1 *}$ (D)

\begin{abstract}
Background: There is accumulating evidence supporting the use of ivermectin as a malaria control tool. Recent findings from the repeat ivermectin mass drug administrations for control of malaria trial demonstrated a reduced incidence of malaria in villages which received repeated ivermectin mass drug administration (MDA; six doses) compared to those who had only one round of ivermectin. Several other studies investigating the benefits of ivermectin for malaria purposes are ongoing/planned.

Main text: While ivermectin MDA offers promising perspectives in the fight against malaria, we highlight the added benefits and anticipated challenges of conducting future studies in onchocerciasis-endemic regions, which are confronted with a substantial disease burden including onchocerciasis-associated epilepsy. Increasing the frequency of ivermectin MDA in such places may reduce the burden of both malaria and onchocerciasis, and allow for more entomological investigations on both the Anopheles mosquitoes and the blackflies. Upfront, acceptability and feasibility studies are needed to assess the endorsement by the local populations, as well as the programmatic feasibility of implementing ivermectin MDA several times a year.

Conclusions: Onchocerciasis-endemic sites would doubly benefit from ivermectin MDA interventions, as these will alleviate onchocerciasis-associated morbidity and mortality, while potentially curbing malaria transmission. Involving onchocerciasis programs and other relevant stakeholders in the malaria/ivermectin research agenda would foster the implementation of pluri-annual MDA in target communities.
\end{abstract}

Keywords: Malaria, Ivermectin, Onchocerciasis, Mass drug administration, Vector control

\section{Multilingual abstracts}

Please see Additional file 1 for translations of the abstract into the five official working languages of the United Nations.

\section{Background}

The use of avermectins for vector control has been considered for decades [1]. Anopheles mosquitoes were shown to have a reduced life expectancy after biting humans who have ivermectin in their blood [2]. Previous experiments with chickens, pigs and cattle have also

\footnotetext{
* Correspondence: robert.colebunders@uantwerpen.be

${ }^{1}$ Global Health Institute, University of Antwerp, Kinsbergen centrum,

Doornstraat 331, 2610 Antwerp, Belgium

Full list of author information is available at the end of the article
}

demonstrated that ivermectin increases mosquito mortality [3-5]. Although research is yet to ascertain which specific component in ivermectin is responsible for its mosquitocidal effects [6], mass drug administration (MDA) of ivermectin as an endectocide has been proposed as an additional tool to reduce malaria transmission [7]. Of note, the deleterious effects of ivermectin are not limited to the mosquito vectors only, but also extend to the malaria parasite itself [8]. Modelling techniques as well as proof-of-concept field studies have shown that treatment with ivermectin in combination with short courses of currently used artemisinin combination MDA, have the potential to reduce malaria transmission $[9,10]$. Safer alternatives such as an ultra-longacting oral ivermectin formulation [11] and ivermectin-

C The Author(s). 2019 Open Access This article is distributed under the terms of the Creative Commons Attribution 4.0 International License (http://creativecommons.org/licenses/by/4.0/), which permits unrestricted use, distribution, and 
based toxic sugar baits [12] equally offer promising perspectives for future malaria control initiatives. The antiparasitic drug moxidectin is under consideration for large scale use against onchocerciasis; but in contrast to ivermectin, moxidectin is unable to knockdown the malaria vector after being ingested during a blood meal [13].

In a recent cluster-randomized study (the repeat ivermectin mass drug administrations for control of malaria [RIMDAMAL] trial) performed in a high malaria transmission area in Burkina Faso [10], Foy et al. randomized villages to either an intervention or a control group. All eligible village residents received a single oral dose of ivermectin $(150-200 \mu \mathrm{g} / \mathrm{kg})$ and albendazole $(400 \mathrm{mg})$, while the intervention villages received five additional doses of ivermectin alone at 3-week intervals over an 18week period. The crude cumulative malaria incidence was lower in the intervention group (648 episodes among 327 children; 2.00 episodes per child) than in the control group (647 episodes among 263 children; 2.49 episodes per child; $P<0.0001)$. After adjusting for sex and village/household clustering, children in the intervention villages had a $20 \%$ decreased risk of malaria compared to those in the control group (risk ratio: 0.80 [95\% CI: 0.70 to 0.91]; risk difference: -0.49 [95\% CI: 0.79 to -0.21$], P=0.0009$ ). While these findings clearly demonstrate the benefits of more frequent ivermectin MDA, other similar trials are needed to confirm them.

\section{Main text}

The RIMDAMAL trial adds to existing evidence suggesting that ivermectin may become a new tool to improve malaria control. Moreover, the trial showed that repeated ivermectin MDA seems safe [10]. Presently, ivermectin is commonly used for the control and treatment of onchocerciasis, a filarial disease caused by the nematode Onchocerca volvulus, which is transmitted by blackflies (Simuliidae). As an endectocide, ivermectin targets ligand-gated chloride channels in invertebrates, which are necessary for their neuromuscular transmission. While ivermectin is very active against $O$. volvulus microfilariae, studies have failed to show an increased mortality among blackflies which fed on ivermectintreated persons [14]. However, the ivermectin dosage and frequency of administration in the previous studies were lower than the RIMDAMAL regimen.

It would therefore be useful to conduct similar RIMDAMAL trials in places with ongoing onchocerciasis transmission, more so because in several endemic settings is Africa, onchocerciasis is still associated with a substantial burden of disease including onchocerciasisassociated epilepsy (OAE) [15]. By implementing ivermectin MDA several times a year, not only malaria but also onchocerciasis-associated morbidity and mortality can be prevented. During such trials in onchocerciasis foci, entomological investigations should be conducted concomitantly to investigate the effect of different ivermectin regimens on Anopheles/blackfly survival. Blood obtained from trial participants can be ingested by noninfected Anopheles/blackflies from an insectary using membrane-feeding methods in a laboratory setting, followed by close monitoring of the insects. Indeed, the membrane-feeding approach is reliable and more ethically acceptable than exposing human baits to natural insects' bites. Another advantage of conducting such research in onchocerciasis-endemic regions is that there are already existing networks of community-directed distributors of ivermectin, with field experience in MDA.

Currently, onchocerciasis transmission is still ongoing in several endemic sites due to suboptimal adherence to yearly community-directed treatment with ivermectin (CDTI) [15]. Consequently, we expect that implementing pluri-annual ivermectin MDA and achieving a satisfactory coverage in these communities would entail a number of constraints including logistical issues, financial limitations, and increased risk of adverse events (Table1). Therefore, while new trials to investigate the strategy of repeated ivermectin treatments to reduce malaria transmission are being planned, feasibility studies should be undertaken using mixed methods. The acceptability, potential endorsement by the local population, programmatic feasibility, and the cost of implementing ivermectin MDA several times a year should be assessed before next big studies are conducted. Additionally, the sustainability of such a scheme would require greater quantities of ivermectin and more local resources for its distribution; this can only be achieved via an increased commitment of pharmaceutical companies and availability of multilateral funds to finance drug access in the long term [7].

An intriguing finding of the RIMDAMAL trial that is of interest for MDA programs, is that a relatively large number of under-five children were treated with ivermectin and no drug-related side effects were observed [10]. These results suggest that the frequent exclusion of children aged 5 years and below during CDTI in many endemic communities needs to be reconsidered. This is important because untreated children who are infected with $O$. volvulus constitute a human reservoir for the parasite. Also, in settings of high onchocerciasis transmission, OAE including nodding syndrome commonly occurs in children as young as 3 years [15]. Moreover, given that the risk of developing OAE depends on the intensity of O. volvulus infection during childhood [20], it is possible that OAE will altogether be averted in children who receive ivermectin early enough as this may prevent a peak microfilarial density capable of triggering seizures. Therefore, clinical trials investigating the safety 
Table 1 Possible challenges to implement multiple ivermectin treatments annually

\begin{tabular}{|c|c|c|c|}
\hline Challenge & Possible explanation & Remarks & Proposed perspectives \\
\hline $\begin{array}{l}\text { Increased } \\
\text { cost }\end{array}$ & $\begin{array}{l}\text { - Reticence from drug manufacturers to } \\
\text { provide additional huge quantities of } \\
\text { ivermectin for free. } \\
\text { - Increased local cost for ivermectin } \\
\text { distribution, because of more logistical } \\
\text { needs and multiplied labour force. }\end{array}$ & $\begin{array}{l}\text { Multiple CDTI per year would increase absolute } \\
\text { cost, but the public health benefits for both } \\
\text { malaria and neglected tropical diseases would } \\
\text { be huge. }\end{array}$ & $\begin{array}{l}\text { - Secure external funding to sustain pluri- } \\
\text { annual CDTI. } \\
\text { - Convince drug manufacturers to continue } \\
\text { providing the drug for free. }\end{array}$ \\
\hline $\begin{array}{l}\text { Reduced } \\
\text { compliance }\end{array}$ & $\begin{array}{l}\text { - Fear of side effects. } \\
\text { - Ignorance, lack of education and } \\
\text { sensitization about CDTI. }\end{array}$ & $\begin{array}{l}\text { Most adverse effects of ivermectin are due to } \\
\text { an initially high microfilarial density or loasis } \\
\text { co-infection. Rarely, adverse effects may still } \\
\text { occur outside these circumstances but often } \\
\text { requires abnormally high drug dosages and/or } \\
\text { frequency of administration. }\end{array}$ & $\begin{array}{l}\text { - Use a test-and-not-treat approach in co- } \\
\text { endemic settings [16]. } \\
\text { - Respect dosages of 150-200 } \mu \mathrm{g} / \mathrm{kg} \text {. } \\
\text { - Educate the population on the health } \\
\text { benefits of CDTI. } \\
\text { - Reassure the population that side effects } \\
\text { will decrease with subsequent doses of } \\
\text { ivermectin, as the microfilarial density } \\
\text { keeps reducing. }\end{array}$ \\
\hline $\begin{array}{l}\text { Drug } \\
\text { resistance }\end{array}$ & $\begin{array}{l}\text { Increased exposure to ivermectin due to } \\
\text { a higher frequency of treatment may } \\
\text { induce ivermectin resistance in the } \\
\text { parasite [17]. }\end{array}$ & $\begin{array}{l}\text { Polytherapy could help prevent drug resistance } \\
\text { to a single drug. During the RIMDAMAL study } \\
\text { for instance, ivermectin was co-administered } \\
\text { with albendazole. }\end{array}$ & $\begin{array}{l}\text { - Monitor drug resistance. } \\
\text { - Provide ivermectin in combination with } \\
\text { other drugs using an integrated MDA } \\
\text { approach [18]. }\end{array}$ \\
\hline $\begin{array}{l}\text { Drug } \\
\text { interactions }\end{array}$ & $\begin{array}{l}\text { Ivermectin can interact with a number } \\
\text { of molecules, including anti-infectious } \\
\text { agents [19]. }\end{array}$ & $\begin{array}{l}\text { Important for drugs that are taken regularly, } \\
\text { such as anti-epileptic drugs or antiretroviral } \\
\text { drugs. }\end{array}$ & $\begin{array}{l}\text { Individuals presenting a risk for drug } \\
\text { interactions should not receive a multi-dose } \\
\text { ivermectin treatment regimen. }\end{array}$ \\
\hline
\end{tabular}

CDTI Community-directed treatment with ivermectin, MDA Mass drug administration, RIMDAMAL Repeat ivermectin mass drug administrations for control of malaria

of ivermectin in children below 5 years and/or $15 \mathrm{~kg}$ of body weight should be considered.

Finally, Foy et al. [10] conducted the RIMDAMAL study only during the rainy season as they expected a higher malaria incidence during that period. Their observations showed that the difference in malaria incidence between the two study groups was widest 1-2 weeks after the third and sixth ivermectin MDA. It is unlikely that the observed pattern is related to rainfall levels during the study, as the authors themselves attributed it to the pharmacokinetics and mosquitocidal activity of ivermectin [10]. Ideally, we suggest a study in which ivermectin MDA would be initiated 1-2 weeks before the rainy season, such that the ivermectin concentration in treated participants will be sufficiently high by the time rainfall resumes. We realise however that we have limited ability to predict rains and that, given the short half-life of ivermectin, such an approach may require repeated/multiple doses of ivermectin in the event of delayed rainfalls.

\section{Conclusions}

As the research agenda concerning the use of ivermectin for malaria control is advancing [7], it would be beneficial to collaborate with onchocerciasis control programs to discuss eventual possibilities of increasing ivermectin MDA frequency in areas which are co-endemic for both onchocerciasis and malaria. Potentially, this may reduce malaria transmission, but it will certainly reduce onchocerciasis-associated morbidity and mortality.

\section{Additional file}

Additional file 1: Multilingual abstracts in the five official working languages of the United Nations. (PDF $488 \mathrm{~kb}$ )

\section{Abbreviations}

CDTI: Community-directed treatment with ivermectin; MDA: Mass drug administration; OAE: Onchocerciasis-associated epilepsy; RIMDAMAL: Repeat ivermectin mass drug administrations for control of malaria

\section{Acknowledgements}

Not applicable.

Authors' contributions

CR, SFJN and KM reviewed the literature and wrote the initial draft. All authors critically reviewed, edited and approved the final manuscript.

\section{Funding}

Colebunders $\mathrm{R}$ received funding from the European Research Council (ERC) grant number 671055, project title NSETHIO.

Availability of data and materials

Not applicable.

Ethics approval and consent to participate

Not applicable.

Consent for publication

Not applicable.

\section{Competing interests}

The authors declare that they have no competing interests.

\section{Author details}

${ }^{1}$ Global Health Institute, University of Antwerp, Kinsbergen centrum, Doornstraat 331, 2610 Antwerp, Belgium. ${ }^{2}$ Department of Pathology, University of Texas Medical Branch, Galveston, USA. 
Received: 12 April 2019 Accepted: 9 August 2019

Published online: 23 August 2019

\section{References}

1. Wilson ML. Avermectins in arthropod vector management - prospects and pitfalls. Parasitol Today. 1993;9:83-7.

2. Chaccour C, Lines J, Whitty CJM. Effect of ivermectin on Anopheles gambiae mosquitoes fed on humans: the potential of oral insecticides in malaria control. J Infect Dis. 2010;202:113-6.

3. Pasay CJ, Yakob L, Meredith HR, Stewart R, Mills PC, Dekkers MH, et al. Treatment of pigs with endectocides as a complementary tool for combating malaria transmission by Anopheles farauti (s.s.) in Papua New Guinea. Parasit Vectors. 2019;12(1):124

4. Pooda HS, Rayaisse J-B, Hien DF de S, Lefèvre T, Yerbanga SR, Bengaly Z, et al. Administration of ivermectin to peridomestic cattle: a promising approach to target the residual transmission of human malaria. Malar J. 2015;13(Suppl 1):496.

5. Chandre F, Hougard JM. Systemic action of ivermectin on Culex quinquefasciatus and Simulium squamosum. Bull Soc Pathol Exot. 1999;92: 71-2 Article in French.

6. Ōmura S, Crump A. Ivermectin and malaria control. Malar J. 2017;16:172.

7. Chaccour CJ, Rabinovich NR, Slater H, Canavati SE, Bousema T, Lacerda M, et al. Establishment of the Ivermectin research for malaria elimination network: updating the research agenda. Malar J. 2015;14:243.

8. Pinilla YT, Lopes S CP, Sampaio V S, Andrade FS, Melo GC, Orfanó AS, et al. Promising approach to reducing malaria transmission by ivermectin: Sporontocidal effect against Plasmodium vivax in the south American vectors Anopheles aquasalis and Anopheles darlingi. PLoS Negl Trop Dis. 2018;12(2):e0006221.

9. Slater HC, Walker PGT, Bousema T, Okell LC, Ghani AC. The potential impact of adding ivermectin to a mass treatment intervention to reduce malaria transmission: a modelling study. J Infect Dis. 2014;210:1972-80.

10. Foy BD, Alout H, Seaman JA, Rao S, Magalhaes T, Wade M, et al. Efficacy and risk of harms of repeat ivermectin mass drug administrations for control of malaria (RIMDAMAL): a cluster-randomised trial. Lancet. 2019;393(10180): $1517-26$.

11. Bellinger AM, Jafari M, Grant TM, Zhang S, Slater HC, Wenger EA, et al. Oral, ultra-long-lasting drug delivery: application toward malaria elimination goals. Sci Transl Med. 2016;8(365):365ra157.

12. Tenywa FC, Kambagha A, Saddler A, Maia MF. The development of an ivermectin-based attractive toxic sugar bait (ATSB) to target Anopheles arabiensis. Malar J. 2017;16:338.

13. Butters MP, Kobylinski KC, Deus KM, da Silva IM, Gray M, Sylla M, et al. Comparative evaluation of systemic drugs for their effects against Anopheles gambiae. Acta Trop. 2012;121:34-43.

14. Boussinesq M, Prud'hom JM, Prod'hon J. The effect of ivermectin on the longevity of Simulium damnosum. Bull Soc Pathol Exot. 1999:92:67-70.

15. Colebunders R, Siewe FJN, Hotterbeekx A. Onchocerciasis-associated epilepsy, an additional reason for strengthening onchocerciasis elimination programs. Trends Parasitol. 2018;34:208-16.

16. Kamgno J, Pion SD, Chesnais CB, Bakalar MH, D'Ambrosio MV, Mackenzie $C D$, et al. A test-and-not-treat strategy for onchocerciasis in Loa loaendemic areas. N Engl J Med. 2017;377:2044-52.

17. Bourguinat C, Pion SDS, Kamgno J, Gardon J, Duke BOL, Boussinesq M, et al. Genetic selection of low fertile Onchocerca volvulus by ivermectin treatment. PLoS Negl Trop Dis. 2007;1 (1):e72.

18. Foy BD, Kobylinski KC, da Silva IM, Rasgon JL, Sylla M. Endectocides for malaria control. Trends Parasitol. 2011;27:423-8.

19. Ivermectin Drug Interactions. Drugs.com. [Accessed 2019 Jun 24]. Available from: https://www.drugs.com/drug-interactions/ivermectin-index.html

20. Chesnais CB, Nana-Djeunga HC, Njamnshi AK, Lenou-Nanga CG, Boullé C, ACZ-K B, et al. The temporal relationship between onchocerciasis and epilepsy: a population-based cohort study. Lancet Infect Dis. 2018;18:1278-86.

Ready to submit your research? Choose BMC and benefit from:

- fast, convenient online submission

- thorough peer review by experienced researchers in your field

- rapid publication on acceptance

- support for research data, including large and complex data types

- gold Open Access which fosters wider collaboration and increased citations

- maximum visibility for your research: over $100 \mathrm{M}$ website views per year

At $\mathrm{BMC}$, research is always in progress.

Learn more biomedcentral.com/submissions 